\title{
Monitoring DIAMOND device for corrosion state evaluation of reinforced concrete structures
}

\author{
Gabriel Samson ${ }^{1}$, Fabrice Deby*,1, Jean-Luc Garciaz², Jean-Louis Perrin² \\ ${ }^{1}$ LMDC, INSAT/UPS Génie Civil, 135 Avenue de Rangueil, 31077 Toulouse cedex 04, France \\ ${ }^{2}$ LERM SETEC, 23 Rue de la Madeleine, 13631 Arles cedex, France
}

\begin{abstract}
The corrosion of steel rebars is a major issue with respect to the durability of reinforced concrete structure. Several corrosion evaluation methods exist: half-cell potential, concrete resistivity or linear polarization resistance (LPR) measurement. However, these techniques are employed at a given moment and are not suitable for continuous corrosion evaluation. This works belongs to the DIAMOND project which aims to produce a new corrosion state measurement monitoring device. The monitoring probe consists on a cylindrical probe. A ring shape counter-electrode CE is plated on the probe side. At the centre of the $\mathrm{CE}$, a reference electrode (RE) is placed for potential measurement. The device is embedded in concrete at $25 \mathrm{~mm}$ of the inspected rebar. The instantaneous ohmic drop observed at the beginning of the polarization measurement is only linked with the concrete resistance which depends on concrete cover and resistivity. A numerical model was developed on Comsol ${ }^{\circledR}$ to create abacuses graph that link concrete resistivity and concrete resistance. Thus, the ohmic drop measure at the beginning of the polarization can now be used to determine regularly concrete average resistivity between the monitoring probe and steel rebar. Two other series of abacus graphs are then introduced in order to determine the polarization resistance of the rebar in front of the monitoring probe (the point of interest (PI)). Two monitoring probes were placed in two types of concrete (one sound concrete and one concrete with chloride). Corrosion potential, concrete resistivity and rebar corrosion rate were monitored over around 200 days. The experimental results obtained with the monitoring probe are finally compared to the results obtained with the surface DIAMOND probe (introduced in the ICCRRR 2018 paper "Alternative methodology for linear polarization resistance assessment of reinforced concrete structure [1]")
\end{abstract}

\section{Introduction}

The corrosion rate of rebar embedded in concrete can significantly vary with time because of external moisture conditions modification. Following the corrosion state of reinforced concrete structure regularly over a long period seems to be a more accurate approach than a one-time measurement. The DIAMOND project [2] developed two types of probes (monitoring and surface) and associate measurement methodologies to simultaneously evaluate three representative parameters of corrosion state, the corrosion potential $\mathrm{E}_{\text {corr }}$, the concrete resistivity $\rho$ and the corrosion rate $i_{\text {corr. }}$. This paper focusses on the monitoring probe. The surface probe is presented in another paper in this conference [1].

The measurement method is based on galvanostatic pulse measurement. This technique is employed since around 30 years to determine the corrosion rate of the rebar/concrete interface and the measurement procedure can be found in many papers [3-9]. However, simultaneous measurement of the three previously quoted corrosion state representative parameters ( $\mathrm{E}_{\text {corr }}, \rho$ and $\left.\mathrm{i}_{\text {corr }}\right)$ cannot be found in literature. The simultaneous acquisition of these three parameters at regular intervals over a long period of time would help the non-destructive evaluation of the reinforced concrete structures.

The monitoring DIAMOND probe will be first presented. Then, the measurement methodology is introduced for both resistivity and corrosion rate assessment. The measurement is then numerically modelled using COMSOL ${ }^{\circledR}$ software. The results are presented in abacus graphs where three parameters are taken into account: concrete cover and resistivity, rebar diameter. The numerical simulations enable both resistivity and corrosion rate assessment. Experiments on two types of concrete (sound concrete and concrete prepared with chlorides) are then performed. The obtained results are finally compared with the results given by the surface probe [1].

\section{Materials and experimental setup}

\subsection{DIAMOND monitoring probe}

The photo of the DIAMOND monitoring probe is presented in Fig. 1. The probe is a $22 \mathrm{~mm}$ cylinder. A ring shape counter electrode (CE) is attached on the probe side. The $\mathrm{CE}$ has a $8 \mathrm{~mm}$ internal diameter and $22 \mathrm{~mm}$ external

* Corresponding author: f_deby@insa-toulouse.fr 
diameter. The probe is placed into the concrete in a previously drilled $24 \mathrm{~mm}$ hole. It is embedded in concrete with mortar in order to limit the influence of environmental factors (rain, sun...) that can heavily modify concrete resistivity on a thin layer of the concrete surface. The electrical contact between the probe and the concrete is performed using a mortar without shrinkage. The potential is measured on the centre of the $\mathrm{CE}$, on a small circular surface ( $5 \mathrm{~mm}$ diameter) with a $\mathrm{Cu} / \mathrm{CuSO}_{4}$ reference electrode (RE). The centre of the RE is placed at $25 \mathrm{~mm}$ from the nearest surface of the rebar. An electrical connection between the rebar and the probe is performed. The injected current $\mathrm{J}_{\mathrm{P}}$ is controlled by a galvanostat developed in our laboratory $\left(\mathrm{J}_{\mathrm{P}}=10 \mu \mathrm{A}\right)$. It was calibrated with an Iso-tech multimeter. In the near future, the probe will be linked to a wireless and selfpowered miniaturized monitoring CAPTAE® system to provide corrosion state data (corrosion potential, concrete resistivity and rebar corrosion rate) on a long-term cycle ( 2 to 5 years).

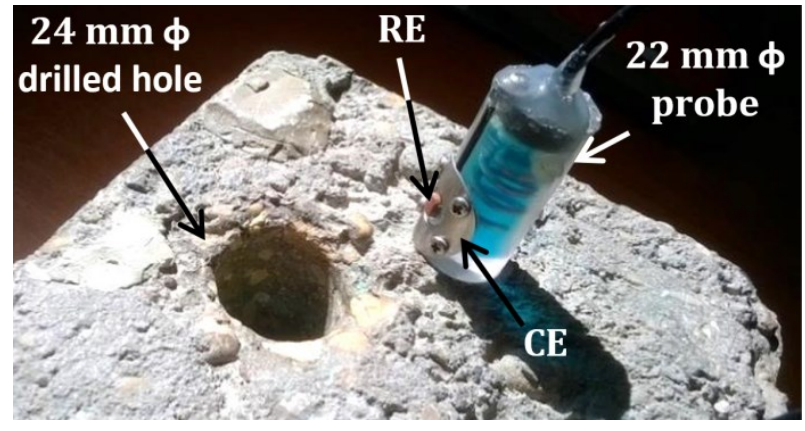

Fig. 1. DIAMOND monitoring probe.

\subsection{Concrete slab specimens}

One concrete slab containing two types of concrete was cast (Fig. 2). The concrete slab $\left(800 \times 210 \times 150 \mathrm{~mm}^{3}\right)$ was prepared with CEM I cement and a very high water/cement ratio of 1.05 . The quality of the produced concrete was voluntarily bad in order to promote corrosion and fast moisture balancing. Half of the slab was prepared with chloride in order to activate the corrosion process. The slab contains two crossing rebars $(\varnothing=10 \mathrm{~mm})$ and six perpendicular rebar. In each concrete, there are 3 rebars of diameter 8,10 and $12 \mathrm{~mm}$ which are respectively placed at 18, 25 and $45 \mathrm{~mm}$ under the concrete surface. The samples were cast and the tests began 8 weeks after their production. The slabs are placed outside in Arles, France.

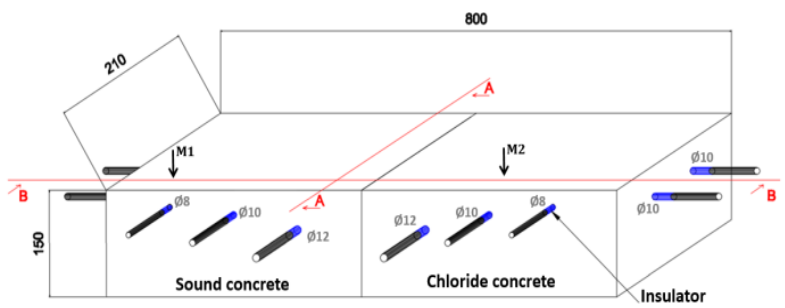

Fig. 2. Concrete slab geometry. Concrete covers are 18, 25 and $40 \mathrm{~mm}$.
Two monitoring probes were implanted in the concrete slab. The first is placed in the sound concrete at $25 \mathrm{~mm}$ of the $8 \mathrm{~mm}$ diameter rebar which is at $18 \mathrm{~mm}$ concrete cover depth (M1 on Fig. 2). The second monitoring probe is located in the part of the slab prepared with chloride and faces the $10 \mathrm{~mm}$ diameter rebar (concrete cover is $25 \mathrm{~mm}-\mathrm{M} 2$ on Fig. 2). The point located on the rebar/concrete interface that faces the RE of the probe is called the point of interest (PI) and is presented on the modelled geometry in Fig. 3. These two rebars will also be investigated with the DIAMOND surface probe which is introduced in a second paper presented at ICCRRR 2018 [1].

\subsection{Resistivity measurement methodology}

The rebar diameter $\mathrm{D}$ and concrete cover $\mathrm{c}$ can be evaluated by non-destructive technique [10]. The polarization of rebar is a transient phenomenon. The rebar / concrete interface can be modelled by a Randles equivalent circuit [3] which associated the polarization resistance $R_{P}$ and the capacitance $C$. This representation is presented in one dimension. In reality, it should take into account the three-dimensional nature of the problem. The rebar is polarized using a galvanostatic method. The instantaneous ohmic drop $\Delta \mathrm{E}_{\Omega}$ observed at the beginning of the polarization is only linked with the concrete resistance $\mathrm{R}_{\Omega}$ which depends on concrete cover, rebar diameter and resistivity:

$$
\Delta \mathrm{E}_{\Omega}=\mathrm{R}_{\Omega} \cdot \mathrm{J}_{\mathrm{P}}
$$

A geometrical factor $\mathrm{k}$ linking the concrete resistivity to the concrete resistance has to be determined:

$$
\rho=k \cdot R_{\Omega}
$$

Several configurations were numerically modelled in order to model most of the cases that could be encountered on-site. Concrete covers ranged from 30 to $120 \mathrm{~mm}$ and rebar diameter ranged from 6 to $32 \mathrm{~mm}$. The distance between the rebar and the probe was kept at $25 \mathrm{~mm}$.

\subsection{Linear polarization resistance measurement methodology}

The steady-state response is then used to determine the linear polarization resistance of the rebar/concrete interface. On steady-state, the relation between potential shift $\left(\mathrm{E}-\mathrm{E}_{\text {corr }}\right)$ and the current density i flowing through the interface is governed by the Butler - Volmer equation:

$$
i=i_{\text {corr }}\left(e^{\frac{E-E_{\text {corr }}}{b_{a}} \ln (10)}-e^{\frac{E-E_{\text {corr }}}{b_{c}} \ln (10)}\right)
$$

The parameters are given in Table 1. 
Table 1. Butler-Volmer parameters implemented in the model.

\begin{tabular}{lll}
\hline Parameters & Unit & Values \\
\hline $\mathrm{E}_{\text {corr }}$ & V/Ref & -0.42 \\
$\mathrm{~b}_{\mathrm{A}}$ & V/dec & 0.3 \\
$\mathrm{~b}_{\mathrm{C}}$ & V/dec & 0.125 \\
\hline
\end{tabular}

At the PI, the surface linear polarization resistance $\mathrm{R}_{\mathrm{P}, \mathrm{S}}$ $\left[\Omega . \mathrm{m}^{2}\right]$ is the ratio between the polarization of the rebar $\left(\Delta E_{P}=E-E_{\text {corr }}\right)$ and the current density $\mathrm{j}_{\mathrm{PI}}$.

$$
R_{P, s}=\frac{\Delta E_{P}}{j_{P I}}
$$

The corrosion rate $i_{\text {corr }}$ is then determined with the SternGeary equation:

$$
i_{\text {corr }}=\frac{B}{R_{P, s}}
$$

where $\mathrm{B}$ is a constant that depends Tafel slopes $\mathrm{b}_{\mathrm{A}}$ and $\mathrm{b}_{\mathrm{C}}[11,12]$ :

$$
B=\frac{b_{A} b_{C}}{\ln (10)\left(b_{A}+b_{C}\right)}
$$

B constant differs from different systems and is difficult to evaluate on-site. It is generally fixed at 26 and $52 \mathrm{mV}$ for active and passive area respectively [13]. In this study the Tafel slopes are fixed and correspond to typical values measured for medium corrosion. In this study, $\mathrm{B}=38 \mathrm{mV}$.

\section{Finite element model}

Only a half of the system was modelled because of the symmetry of the problem. The current $J_{P}$ was injected through the $\mathrm{CE}$ and was equal to $10 \mu \mathrm{A}$ for all numerical experiments. The RE was a cylinder in contact with the sealing mortar and the $\mathrm{CE}$ was a disc with a hole in it to enable RE contact with the sealing mortar (Fig. 3). The distance between the RE and the rebar was $25 \mathrm{~mm}$. RE and CE resistivity was $10^{-5} \Omega . \mathrm{m}$. The $2 \mathrm{~mm}$ width contact mortar resistivity was equal to the concrete resistivity. Different rebar diameters were modelled (6, 10, 16 and $32 \mathrm{~mm}$ ). Concrete cover ranged between 30 and $120 \mathrm{~mm}$.

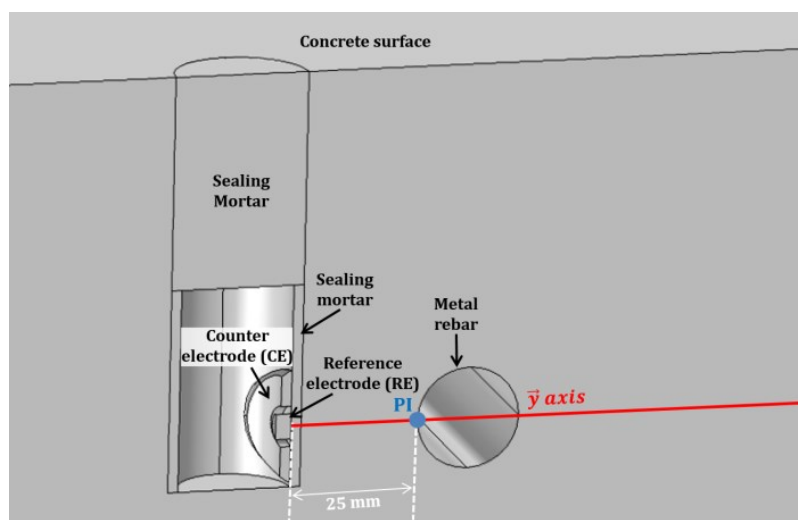

Fig. 3. Modelled geometry for $\mathrm{D}=20 \mathrm{~mm}$ and $\mathrm{c}=50 \mathrm{~mm}$.

A very small electric resistance $(0.00001 \Omega)$ was implemented on the rebar/concrete interface to model the polarization resistance short-cut at the beginning of the polarization. To model the steady-state of the polarization of the rebar, the Butler-Volmer equation (Table 1) was implemented on the entire rebar surface.

Tetrahedral elements were used for discretization. The maximum element size was fixed at $0.5 \mathrm{~mm}$. The mesh was refined around the probe, the rebar surface and the $\vec{y}$ axis. The $\vec{y}$ axis was the axis passing through the centre of the RE and the PI of the rebar. It is represented by a red line in Fig. 3.

\section{Numerical results}

\subsection{Concrete cover resistivity abacus graph}

The initial potential $\mathrm{E}_{\text {corr }}$ of the rebar is $-0.42 \mathrm{~V} / \mathrm{Ref}$. At the beginning of the polarization, the instantaneous ohmic drop $\Delta \mathrm{E}_{\Omega}$ can be measured by the $\mathrm{RE}$ and is used to determine the concrete cover resistivity. In order to visualize the influence of concrete resistivity on the instantaneous ohmic drop, Fig. 4 is introduced. It represents the evolution of the potential along the $\vec{y}$ axis (axis presented in Fig. 3). The instantaneous ohmic drop can be observed on the two small thickness curves.

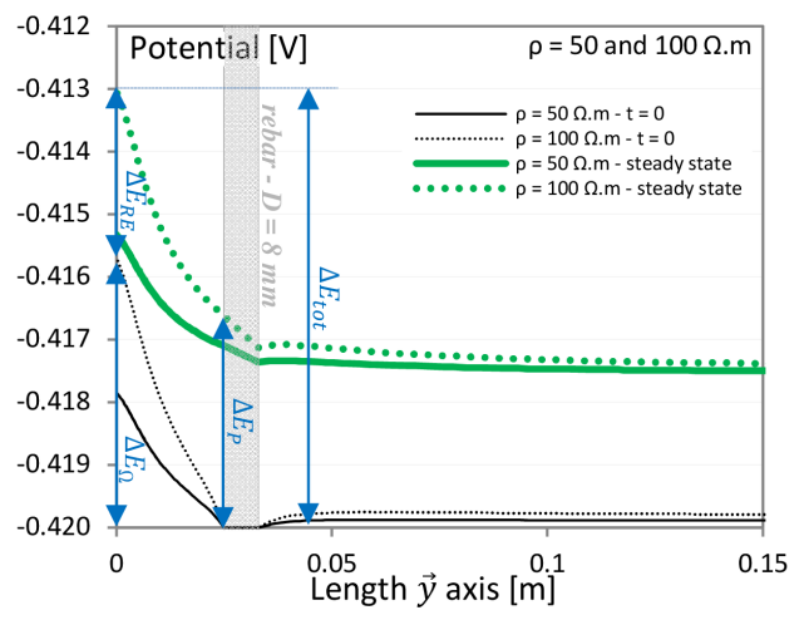

Fig. 4. Potential evolution on the $\overrightarrow{\boldsymbol{y}}$ axis for two concrete resistivity (50 and $100 \Omega . \mathrm{m})$. Rebar diameter is $8 \mathrm{~mm}$ and concrete cover is $50 \mathrm{~mm}$. The instantaneous ohmic drop $\Delta \mathrm{E}_{\Omega}(\mathrm{t}$ 
$=0$ ), the polarization of the rebar $\Delta \mathrm{Ep}_{\mathrm{p}}$ the total potential shift $\Delta \mathrm{E}_{\text {tot }}$ measured at the RE (steady-state) are introduced for the $100 \Omega$.m resistivity simulation.

The resistivity of the concrete significantly modifies the ohmic drop measured at the RE. At the beginning of the polarization, the potential at the rebar concrete interface remains equal to the corrosion potential $\left(E_{\text {corr }}=-0.42 \mathrm{~V} / \mathrm{Ref}\right)$. This type of simulation was repeated for several concrete cover / rebar diameter in order to determine the geometrical factor (Fig. 5), linking the concrete resistivity to the concrete resistance.

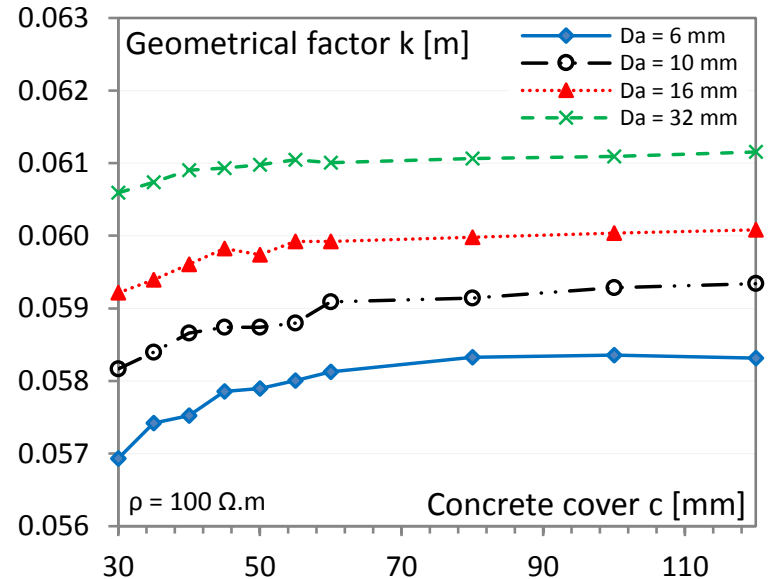

Fig. 5. Geometrical factor $\mathrm{k}$ depending on rebar diameter and concrete cover.

As it was expected, the geometrical factor mostly depends on the rebar diameter and is not significantly influence by the concrete cover because the probe is embedded in the concrete, just in front of the rebar. This abacus graph will be used to experimentally measure the concrete resistivity evolution between the probe and the rebar.

\subsection{Corrosion rate abacus graph}

To determine the surface linear polarization resistance $\mathrm{R}_{\mathrm{P}, \mathrm{s}}$, both rebar polarization $\Delta \mathrm{E}_{\mathrm{P}}$ and current density at the PI $j_{P I}$ must be determined and both depend on several parameters of the problem (injected current, rebar diameter, concrete cover). Fig. 4 (high thickness curves) presents the evolution of the potential along the $\vec{y}$ axis on steady-state. The rebar is polarized $\left(\Delta \mathrm{E}_{\mathrm{P}} \neq 0\right)$. Due to the three dimensional nature of the problem, the rebar polarization $\Delta \mathrm{E}_{\mathrm{P}}$ is different from potential switch $\left(\Delta \mathrm{E}_{\text {tot }}-\Delta \mathrm{E}_{\Omega}\right)$ observed on the surface between the beginning and the stabilized state of the polarization $\left(\Delta \mathrm{E}_{\mathrm{P}} \neq \Delta \mathrm{E}_{\mathrm{P}, \mathrm{RE}}\right)$.

These types of simulation are made for a wide range of all the previously quoted parameters and summarized on several abacus graphs. For the sake of clarity, only the abacus graph obtained for 100 S.m resistivity are presented but the numerical simulations were performed for 12 different resistivity ranging from 20 to $2000 \Omega$.m. The first abacus graph is used to determine the current density at the PI and is presented on Fig. 6.

The current density received at the PI significantly depends on the rebar diameter (Fig. 6). When the rebar diameter is small, the current lines are tightened and explain why the ratio $\mathrm{j}_{\mathrm{PI}} / \mathrm{j}_{\mathrm{P}}$ is maximum (around 0.045 for $\mathrm{D}=6 \mathrm{~mm}$ ). With bigger rebar, the current is more spread which explain why the ratio $\mathrm{j}_{\mathrm{PI}} / \mathrm{j}_{\mathrm{P}}$ is smaller (around 0.02 for $\mathrm{D}=32 \mathrm{~mm}$ ). The concrete cover does not influence the $\mathrm{j}_{\mathrm{PI}} / \mathrm{j}_{\mathrm{p}}$ ratio.

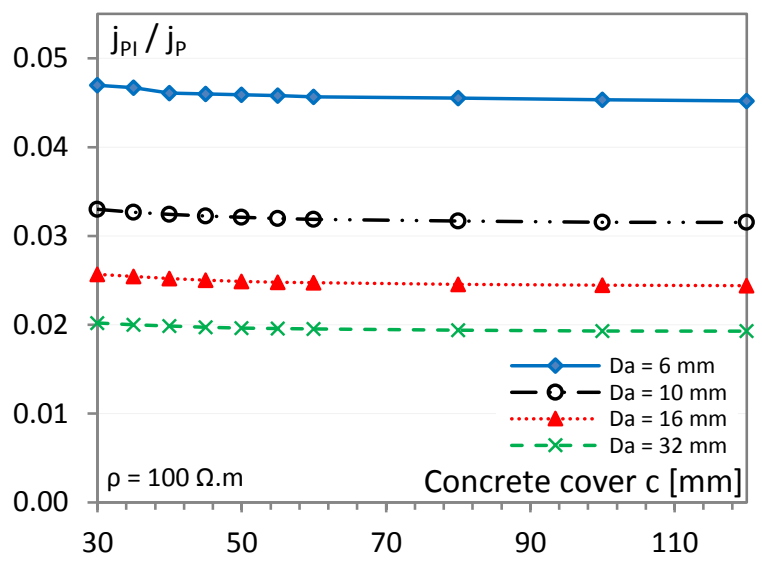

Fig. 6. Ratio between the current density at the PI jpI and the injected current density jp depending on concrete cover for a 100 $\Omega$.m resistivity and four different rebar diameters.

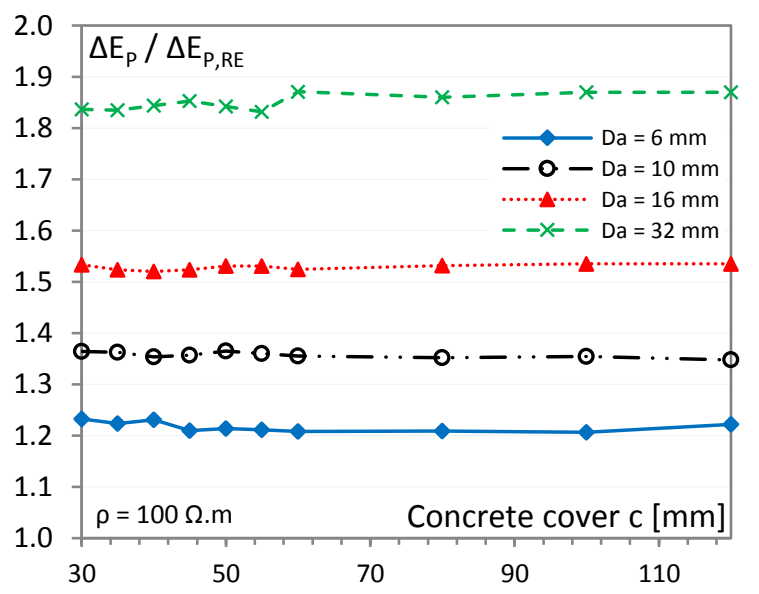

Fig. 7. Ratio between the polarization at the PI $\Delta \mathrm{EP}$ and the polarization on the surface $\Delta \mathrm{E}_{\mathrm{P}, \mathrm{RE}}$ depending on concrete cover for a $100 \Omega . m$ resistivity and 5 different rebar diameters.

The ratio between the polarization at the PI $\Delta \mathrm{E}_{\mathrm{P}}$ on the rebar and the potential shift $\Delta \mathrm{E}_{\mathrm{P}, \mathrm{RE}}$ measured at the $\mathrm{RE}$ is introduced in Fig. 7. As observed in the previous abacus graph (Fig. 6), concrete cover does not influence this ratio. However, a significant influence of the rebar is again noticed. Contrary to the previous abacus graph, the denominator of the ratio is not constant and is also influenced by the parameters of the study. The ratio is maximum for big rebar diameter because the polarization measured on the $\mathrm{RE} \Delta \mathrm{E}_{\mathrm{P}, \mathrm{RE}}$ significantly decreases when the rebar diameter increases.

\section{Experimental results}


Without polarization, the potential measured by the RE is the corrosion potential $E_{\text {corr }}$ of the rebar/concrete interface. According to the measured values, a corrosion risk can be established [13].

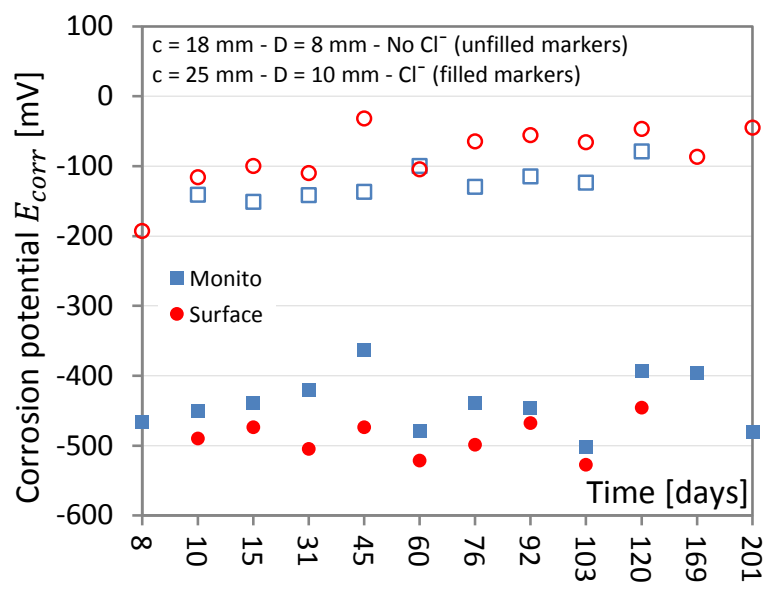

Fig. 8. Corrosion potentials evolution.

The corrosion potentials measured on the rebar placed in sound concrete (unfilled markers) and on concrete with chloride (filled markers) with the two DIAMOND probes (monitoring (square markers) and surface (circle markers)) are presented in Fig. 8. The two probes gave similar corrosion potentials. In sound concrete the corrosion potential remains high (around - $100 \mathrm{mV} / \mathrm{Ref}$ ) which indicates a moderate risk of corrosion. The rebar placed in the concrete prepared with chloride presented lower corrosion potentials (around - $480 \mathrm{mV} / \mathrm{Ref}$ ) which indicates a high risk of corrosion.

The resistivity measurements are introduced on Fig. 9 and Fig. 10. Fig. 9 focussed on the measurements performed on the rebar placed in sound concrete. Both surface and monitoring probes gave resistivity value in the same order of magnitude (around 120 S.m in average). The obtained values significantly varied with time because the slab was placed outside. With this bad quality concrete and small concrete cover the resistivity of the concrete cover highly depends on the external weather conditions.

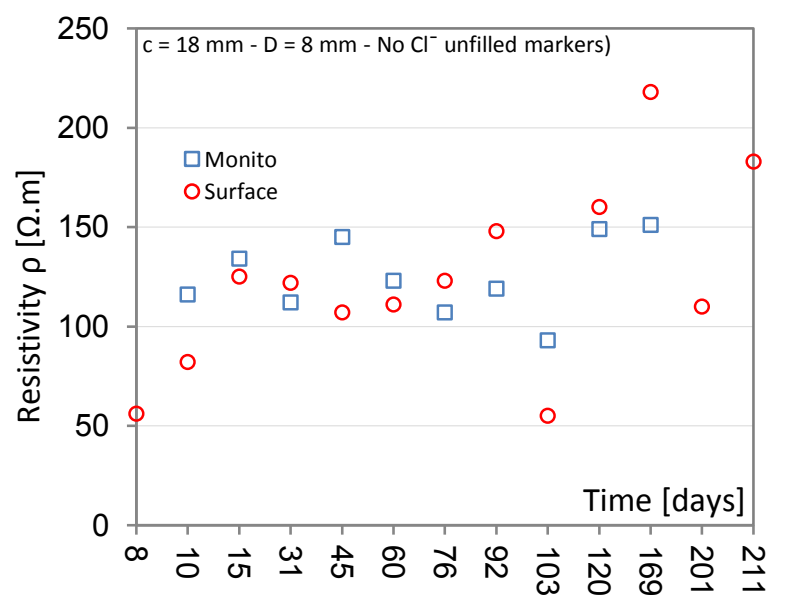

Fig. 9. Concrete resistivity evolution for the slab without chlorides.
The resistivity values obtained on the concrete prepared with chlorides are presented in Fig. 10. The resistivity values measured are logically lower than the values measured on sound concrete. The resistivity measured with the monitoring probe were around $80 \Omega . \mathrm{m}$ while the concrete cover resistivity were lower (around 40 $\Omega . \mathrm{m}$ in average).

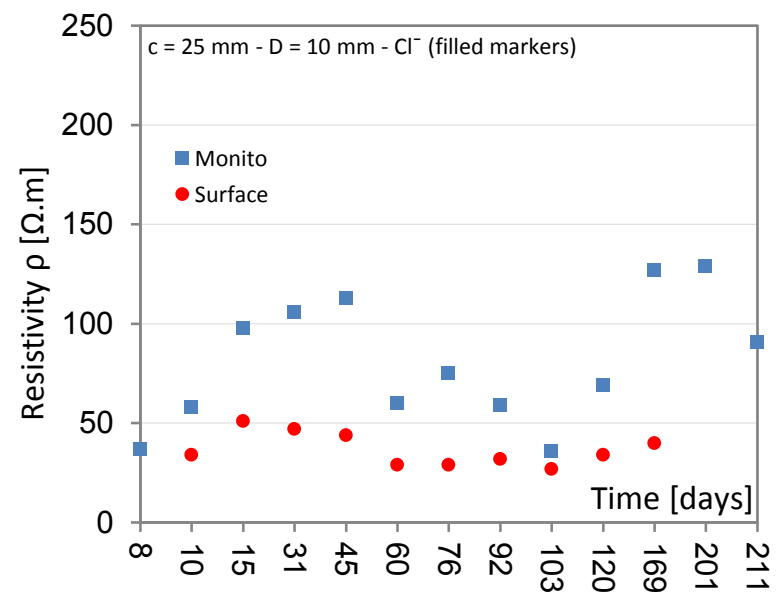

Fig. 10. Concrete resistivity evolution for the slab with chlorides.

The corrosion rates measured are then presented in Fig. 11. For sound concrete, both monitoring and surface probes gave similar corrosion rate values (around $0.04 \mu \mathrm{A} / \mathrm{cm}^{2}$ in average) which indicate a negligible corrosion rate according to. These very small corrosion rate values are in agreement with the high corrosion potentials observed (Fig. 8).

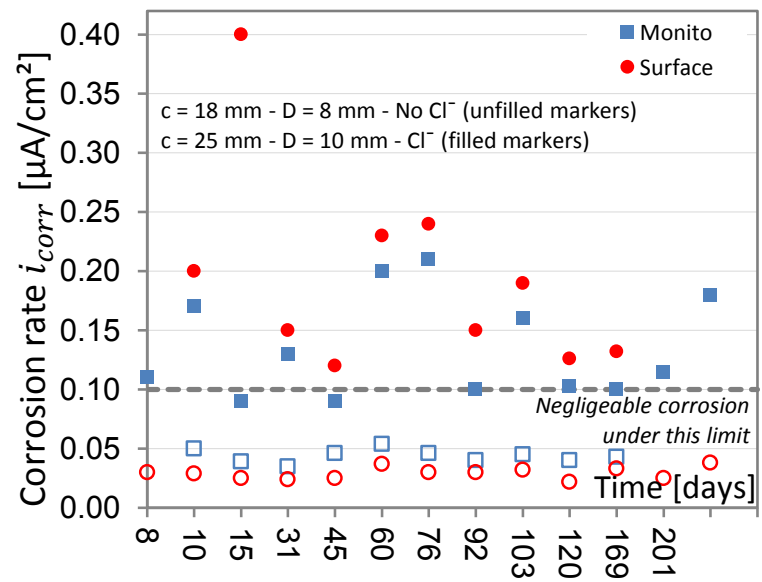

Fig. 11. Corrosion rate evolution.

Higher corrosion rates were measured on the rebar embedded in the concrete with chloride (Fig. 11 - filled markers). These corrosion rate values are more variable than the values observed in sound concrete which indicate that the corrosion rate is influenced by the external climatic conditions when the corrosion is active. 


\section{Conclusions}

This article presented a new monitoring probe for corrosion state evaluation of reinforced concrete structures. The DIAMOND monitoring was introduced and the measurements principles were presented. Numerical simulations of the probe were realized in order to convert the information collected by the probe into corrosion state information of the rebar. These numerical investigations indicated that the measurements are significantly influenced by concrete resistivity and rebar diameter. The rebar was polarized with a galvanostatic method (constant injected current of $10 \mu \mathrm{A}$ ). The collected signal was then analyzed using abacus graphs built with the numerical simulations. The instantaneous ohmic drop was used to determine the concrete resistivity between the probe and the rebar while the steady-state response was used to determine the corrosion rate. The corrosion rate results are then compared with the measurements performed with the surface DIAMOND probe which was presented in another article in ICCRRR 2018 [1]. Good results agreements were observed between these two probes. Further investigations are required to take into account the rebar framework density which will modify the current distribution.

\section{References}

1. G. Samson, F. Deby, J.-L. Garciaz, J.-L. Perrin, ICCRRR, Cape Town, (2018).

2. DIAMOND project, Proj. Diam. - Diagn. Corros. Béton Armé - Sonde Captae. (2017). https://www.projetdiamond.com

3. C.J. Newton, J.M. Sykes, Corros. Sci. 28 (1988) 10511074.

4. B. Elsener, O. Klinghoffer, T. Frolund, E. Rislund, Y. Schiegg, H. Böhni, Repair of Concrete Structures conférence, Norway, (1997).

5. P.V. Nygaard, Non-destructive elecrochemical monitoring of reinforcement corrosion, $\mathrm{PhD}$ thesis, Technical University of Denmark, (2009).

6. P.V. Nygaard, M.R. Geiker, B. Elsener, Mater. Struct. 42 (2009) 1059-1076.

7. P.V. Nygaard, M.R. Geiker, Mater. Corros. 63 (2012) 200-214.

8. C. Andrade, C. Alonso, Constr. Build. Mater. 15 (2001) 141-145.

9. C. Andrade, C. Alonso, Mater. Struct. 37 (2004) 623643.

10. G. Klysz, J.-P. Balayssac, S. Laurens, NDT E Int. 37 (2004) 221-227.

11. A. Clément, S. Laurens, G. Arliguie, F. Deby, Eur. J. Environ. Civ. Eng. 16 (2012) 491-504.

12. A. Poursaee, Cem. Concr. Res. 40 (2010) 1451-1458.

13. RILEM TC 154, (2004). 